\title{
Restabelecendo as relações fundamentais: da linguística histórica à linguística moderna
}

\author{
Allana Cristina Moreira Marques ${ }^{1}$
}

\section{Resumo}

Neste trabalbo, apresentamos uma leitura da noção de relação na reflexão teórica do neogramático Hermann Paul em cotejo com a elaboração teórica de Ferdinand de Saussure. Essa leitura demonstrará como a noção de relação é tratada, na reflexão de Paul, de maneira secundária, principalmente, em função do entendimento da mudança, diferentemente do que acontece na reflexão saussuriana, na qual ela ocupa lugar de destaque. Para tanto, procederemos com uma revisão bibliográfica da obra Princípios Fundamentais da História da Língua de Hermann Paul, dando ênfase às passagens em que a noção de relação é mobilizada por ele e, oportunamente, estabeleceremos uma comparação com a proposta teórica saussuriana que se apresenta na edição do Curso de Linguística Geral.

Palavras-chave: Relação. Linguística.

Neogramáticos. Ferdinand de Saussure

1 Doutoranda no Programa de Pós-Graduação em Estudos Linguísticos na Universidade Federal de Uberlândia. 


\section{Introdução}

Em análise à edição do Curso de Linguística Geral (CLG), cuja autoria foi atribuída postumamente a Ferdinand de Saussure, e também a notas manuscritas do linguista genebrino $^{2}$, observamos que a noção de relação constituiu uma importante base epistemológica dos estudos propostos por ele, figurando pressuposto basilar para o entendimento de seus mais diferentes conceitos, imprescindíveis para a fundação da Linguística moderna.

A nosso ver, além da produtividade dessa noção na elaboração dos conceitos linguísticos saussurianos - tais como, língua, signo, arbitrariedade, linearidade, diacronia, sincronia, entre outros - o movimento teórico em torno dela teve por efeito um distanciamento daquilo que é proposto por Saussure em relação aos estudos desenvolvidos por seus antecessores e por seus contemporâneos, os neogramáticos. Desse modo entendido, observamos que essa noção, diferentemente do que acontece na proposta dos linguistas históricos do final do século XIX, resultou em importantes consequências epistemológicas para a teorização saussuriana, tal qual a construção de um novo objeto de estudo e, por conseguinte, a reorganização do campo de investigações da Linguística.

Assim, procurando observar de que modo Saussure se distancia de seus contemporâneos ao dar às relações um novo tratamento no estudo linguístico ${ }^{3}$, investigaremos como essa noção foi antes mobilizada nos estudos históricos realizados pelos neogramáticos. Para tanto, tomamos como objeto de análise o estudo do neogramático Hermann Paul em cotejo à teoria de Ferdinand de Saussure, no intuito de refletirmos sobre como a noção de relação ganhou novo estatuto na teoria saussuriana, o que a nosso ver permitiu que Saussure, ainda que imerso nas investigações históricocomparatistas de seu tempo, rompesse com os estudos eminentemente históricos, reorganizando o campo do saber linguístico.

\footnotetext{
2 Para uma análise mais detalhada da noção de relação na elaboração teórica de Ferdinand de Saussure, conferir Marques (2015, 2016, 2017, 2018).

${ }^{3}$ A centralidade dessa noção para a teoria saussuriana já foi lida por importantes autores que se dedicaram à investigação da produção saussuriana, dentre os quais destacamos: Normand (2009, p. 33), segundo a qual, "será a realidade das relações, constitutivas do sistema da língua, ponto de partida e ponto de chegada do raciocínio" saussuriano; Benveniste (2005[1966], p. 23), para quem, na proposta de Saussure, "a noção de positivista do fato linguístico é substituída pela de relação".
} 


\section{Saussure e os estudos histórico-comparatistas}

Embora os anos de formação em Leipzig - 1876 a 1880 - sejam os mais representativos da bibliografia de Saussure no que diz respeito aos seus estudos históricos, a Linguística Evolutiva sempre esteve presente nas reflexões saussurianas, mesmo aquelas apresentadas anos depois nos cursos de Linguística Geral. Durante os anos na Alemanha, nos quais Saussure se dedicou à escrita de seu famoso Mémoire sur le système primitif des voyelles dans les langues indo-européenes, o linguista teve contato com grandes nomes do movimento neogramático. Frequentou algumas lições de K. Brugmann e de Osthoff - autores do "Manifesto Neogramático" de 1878 e reconhecidos como fundadores do movimento bem como os cursos História da língua alemã, ministrado por Braune; de Eslavo e de Lituano, ministrados por Leskien, também representantes neogramáticos (DE MAURO, 1973, p. 327).

Além dos estudos históricos realizados pelo linguista e o contato com grandes nomes do movimento neogramático, a afamada carta escrita por Ferdinand Saussure e enviada a Meillet em 1894 também testemunha, por um lado, o forte interesse de Saussure pelos estudos históricos da língua. Por outro, porém, ela nos permite entrever a insatisfação do mestre com a terminologia linguística de seu tempo. Vejamos:

(...) Sem cessar, a inépcia absoluta da terminologia corrente, a necessidade de reformá-la e de mostrar qual espécie de objeto é a língua em geral vêm estragar o meu prazer histórico, embora eu não tenha nenhum desejo mais caro do que não ter que cuidar da linguagem em geral (SAUSSURE apud BENVENISTE, 1964, p. 94, tradução nossa).

A insatisfação com os estudos históricos, em especial, aqueles elaborados pelos neogramáticos, também pode ser observada em um importante trecho da edição do CLG. Ao discorrer sobre as três fases que a Linguística passou antes de encontrar seu verdadeiro objeto, Saussure ressalta os esforços desta escola em direção ao objeto linguístico, mas também sua ineficácia em esclarecer toda a questão linguística:

Seu mérito [dos neogramáticos] consistiu em colocar em perspectiva histórica todos os resultados da comparação, e por ela encadear os fatos em sua ordem natural. Graças aos neogramáticos, não se viu mais na língua um organismo que se desenvolve por si, mas um produto do espírito coletivo dos grupos linguísticos. Ao mesmo tempo, compreende-se quão errôneas e insuficientes eram as ideias da Filologia e da Gramática comparada. Entretanto, por grandes que sejam os serviços prestados por essa escola, não se pode dizer que tenha esclarecido a 
totalidade da questão, e, ainda hoje, os problemas fundamentais da Linguística Geral aguardam uma solução (SAUSSURE, 2012, p. 35-36).

Uma leitura que contemple a produção teórica de Saussure em cotejo com os estudos dessa escola nos mostra que o linguista genebrino, para além das questões puramente terminológicas, avançou teoricamente, estabelecendo, como aponta Normand (2011), uma novidade crítica em relação aos teóricos contemporâneos.

\section{A noção de relação no estudo de Hermann Paul}

Reconhecido como um dos representantes do movimento neogramático ${ }^{4}$, Hermann Paul, em seu livro Princípios fundamentais da história da língua, publicado pela primeira vez em 1880, apresenta questões fundamentais relacionadas ao estudo da mudança e mobiliza importantes conceitos para o entendimento histórico da língua.

Neste estudo, a noção de relação, alvo de nossa investigação no presente trabalho, é, por vezes, movimentada na explicação dos fenômenos linguísticos gerais. Todavia, esses fenômenos são abordados por Paul, principalmente, na reflexão que busca explicar o mecanismo da mudança linguística. Desse modo os fenômenos fundamentalmente linguísticos, nos quais é possível observar o funcionamento de relações, são abordados por Paul apenas de maneira secundária. Trata-se, como aponta o título do livro, dos princípios fundamentais da história da língua e não dos princípios linguísticos propriamente ditos. A pouca atenção dada aos fenômenos linguísticos gerais, isto é, aqueles que, para além das leis da mudança, regem o mecanismo linguístico, a nosso ver, constitui um fator que levou Saussure a denunciar a insuficiência dessa escola no que tange à resolução dos problemas de Linguística Geral ${ }^{5}$ (SAUSSURE, 2012, p. 36).

\footnotetext{
${ }^{4}$ Os últimos anos do século XIX foram marcados, na história dos estudos linguísticos, pela geração de estudiosos que, na Universidade de Leipzig, propuseram um novo modo de conceber a mudança linguística para além do viés comparatista tradicional. O marco que deu início a este movimento, o qual rendeu à investigação linguística, sobretudo, da mudança, uma nova direção, é reconhecido na publicação do primeiro número da revista Morphological Investigations no ano de 1878.

${ }^{5}$ Embora em seu capítulo introdutório Hermann Paul aponte a necessidade de uma ciência de princípios que se ocupe das condições gerais da vida da língua e também dos fatores que permanecem regulares, é, especialmente, o estudo da mudança e de seu funcionamento que interessa ao estudioso. Os aspectos gerais da língua aparecem, nesta reflexão, como dados. Sobre os agrupamentos linguísticos - os quais poderiam nos remeter a uma discussão geral do funcionamento linguístico -, por exemplo, Paul afirma que "Não nos compete aqui examinar as leis gerais segundo as quais se formam estes grupos. Para isso remeto para a introdução de Steinthal à Psicologia e Linguística. Aqui só nos interessa dar uma ideia do conteúdo e acção desses grupos" (PAUL, 1966 [1880], p. 35).
} 


\title{
As forças e relações constantes e as relações no tempo
}

No capítulo de introdução de seu livro, Paul afirma que a língua é um objeto de contemplação histórica. O estudo histórico da língua, porém, segundo ele, deve ser acompanhado de uma investigação que se ocupe das condições gerais da vida da língua, buscando analisar "a natureza e acção [d] os factores que se mantêm regulares dentro de toda a mutação" (PAUL, 1966 [1880], p. 13). A esta ciência de princípios o problema que se coloca é: "como é possível, na hipótese de forças e relações constantes, haver uma evolução histórica, um progresso das formas mais simples e primitivas para as mais completas?" (PAUL, 1966 [1880], p. 14, grifo nosso). Com base nesta problemática, Paul delimita que enquanto a parte histórica deve se deter na compreensão da evolução ou mudança da língua, a parte geral da linguística deve se dedicar aos fatores - forças e relações constantes, como vimos, hipotéticas - que permanecem aquém da mudança.

Ainda nessa reflexão, na qual Paul procura estabelecer as bases para uma ciência histórica linguística, diferenciando seu método, bem como seus objetivos, daquele utilizado pelas ciências exatas, a noção de relação é novamente mobilizada. Vejamos:

\begin{abstract}
Mas também estaríamos em erro se pensássemos que com a simples associação de pedaços de ciências diferentes já obteríamos a espécie de ciência que temos em vista. Não, restam-lhes ainda tarefas de que as ciências exactas ${ }^{6}$ - das quais ela usa como meio - não se ocupam. Estas limitam-se a comparar os processos isoladamente, sem se preocuparem com as suas relações no tempo, só interessadas em descobrir as concordâncias e divergências e, com ajuda disso, o que permanece sempre igual a si próprio no meio de toda a mutação dos fenómenos. A noção de evolução é-lhes absolutamente estranha, parece ser mesmo incompatível com os seus princípios, e por isso elas se encontram em oposição aberta com as ciências históricas? (PAUL, 1966 [1880], p. 14, grifo nosso).
\end{abstract}

Paul, tal qual podemos verificar no excerto citado, atesta que a ciência que ele tem em vista, de modo algum, pode ser resultado da associação de diferentes ciências. À ciência histórica estão reservadas tarefas das quais as ciências exatas não se ocupam. Diferentemente destas que se detêm na comparação dos processos isolados, procurando concordâncias e divergências, a ciência de que fala Paul deverá se deter sobre as relações no tempo estabelecidas entre os processos, e não sobre os processos isoladamente. Para essa

\footnotetext{
${ }^{6}$ Paul aponta a matemática e a psicologia como ciências exatas, embora a psicologia seja entendida, hoje, como uma ciência humana.

${ }^{7}$ Neste capítulo introdutório, como pode ser observado a partir do excerto apresentado, Paul se propõe a estabelecer os limites da ciência histórica linguística e, tal qual Saussure na delimitação da Linguística que seria reconhecida com a Linguística moderna, se preocupa em delinear o campo de estudos, a metodologia e o objeto.
} 
tarefa, Paul ressalta que a noção de evolução - ignorada pelas ciências exatas - é fundamental. Nota-se, nesse sentido, que a relação no estudo da mudança, especificamente, as relações no tempo, deve ser entendida no cotejo com a noção de evolução.

A partir do último trecho e dos excertos anteriores, advertimos que, já neste primeiro momento de reflexão, Paul parece distinguir as forças e as "relações constantes" aquelas resistentes à mudança - das "relações no tempo", que testemunham o caráter evolutivo da língua, mas a distinção entre elas não parece implicar grandes efeitos teóricos tal qual na elaboração saussuriana. $\mathrm{Na}$ teorização de Saussure, a esta distinção é dada importância fundamental, e o modo de conceber cada tipo de relações e o lugar a elas estabelecido permitirão que Saussure avance teoricamente no que se refere à teorização dos neogramáticos. Vejamos a distinção colocada pelo linguista genebrino:

A Linguística sincrônica se ocupará das relações lógicas e psicológicas que unem os termos coexistentes e que formam sistemas, tais como são percebidos pela consciência coletiva. A Linguística diacrônica estudará, ao contrário, as relaçoes que unem termos sucessivos percebidos por uma mesma consciência coletiva e que substituem uns aos outros sem formar sistema entre si (SAUSSURE, 2012, p. 142, grifos nossos).

Ainda com vistas a situar a ciência histórica da língua, Paul procura diferenciar seus estudos daqueles realizados pela gramática comparativa:

Opôs-se à gramática comparativa, que se ocupa das relações mútuas de famílias de línguas aparentadas cuja origem comum se perdeu, à gramática histórica, que investiga a continuação da evolução baseando-se num ponto de partida que lhe é transmitido pela tradição (PAUL, 1966 [1880], p. 33).

Como podemos observar no trecho selecionado, a noção de relação opera uma distinção fundamental nessa reflexão. É, principalmente, o modo de concebê-la que diferenciará os estudos puramente comparativos dos estudos históricos da língua. Isso porque, como aponta Paul, a Gramática Comparada operou sobre as relações de parentesco das línguas, isto é, sobre as relações mútuas de famílias linguísticas objetivando alcançar a língua original. Paul denuncia que essa escola sequer se preocupou com as relações no tempo, abdicando das questões evolutivas. Desse modo, podemos afirmar que a noção de relação é utilizada por Paul na definição do objeto da ciência histórica proposta, isto é, as relações no tempo, de modo a acompanhar a evolução linguística, e, concomitantemente, na distinção com a gramática comparada, que estuda as relações de famílias aparentadas. 
Com base nas reflexões veiculadas pelo CLG, é possível afirmar que Saussure reconhece o passo dado pelos neogramáticos no que se refere à mudança de perspectiva efetuada no âmbito das relações estudadas. Segundo Saussure (2012, p. 35), essa nova escola foi responsável por "colocar em perspectiva histórica todos os resultados da comparação". Era objetivo desse estudo analisar, então, o processo de evolução das línguas e não mais as relações de parentesco que levariam à língua-mãe.

Entende-se, desse modo, que as relações exclusivamente comparativas de antes, as quais, tal qual o conjunto de conceitos errôneos do método comparativo, "não correspondem a nada na realidade e [...] são estranhos às verdadeiras condições de toda linguagem" (SAUSSURE, 2012, p. 34), passaram a ser consideradas pelo viés histórico. Apesar da importância da mudança de perspectiva efetuada pelos historiadores, vemos que Saussure, por sua vez, ainda deu às relações em Linguística um novo tratamento. Era preciso diferenciar as relações no tempo, constitutivas do objeto teórico da Linguística Histórica, daquelas estabelecidas em um estado de língua, no interior do sistema linguístico.

\section{Das relações interiores diretas e das relações interiores indiretas}

Na elaboração sobre os processos fundamentais que se produzem nos indivíduos e que, segundo Paul, aludem à natureza histórica da língua, a noção de relação é movimentada no entendimento de fenômenos, com base no que é exposto pelo neogramático, que parecem auxiliar no "esclarecimento das condições do devir histórico" (PAUL, 1966 [1880], p. 15). É o que acontece, primeiramente, no entendimento da ligação estabelecida entre o conteúdo psíquico e o conteúdo físico, segundo o neogramático, constitutivos dos processos fundamentais. Essa reflexão, na qual Paul tematiza sobre processos mais gerais, o levará à compreensão das transformações de associações que ocorrem nas formações linguísticas. Desse modo, observamos uma vez mais a noção de relação sendo mobilizada essencialmente em favor da investigação da mutação.

Paul observa, a princípio, na reflexão sobre a ação recíproca dos indivíduos, isto é, a comunicação, e o que a possibilita, que não é possível contar com o espírito total e com elementos desse espírito total, mas apenas verificar os processos fundamentais que se produzem na "psicologia individual" ou na "alma" de cada indivíduo. Segundo o autor, as formações linguísticas de cada indivíduo - as associações entre ideias e sons, expressões, 
imagens, etc. -, surgem em decorrência do fato de que ele vive em uma sociedade com uma série de outros indivíduos. Uma compreensão dessas formações, de acordo com o que é dito por ele, exige, porém, que observemos os diferentes estágios que elas percorrem nos indivíduos, observando suas evoluções a partir de um viés histórico. Assim, nas palavras Paul:

Para produzir numa outra alma a associação de ideias correspondente a uma nascida em si própria, a alma não pode fazer mais do que, por meio dos nervos motores, criar um produto psíquico, o qual por sua vez, excitando os nervos sensitivos do outro indivíduo, produz na alma dele as ideias correspondentes, e mesmo igualmente associadas. De entre os produtos psíquicos que servem este fim, os mais importantes são precisamente os sons da língua. Além disso, temos os outros sons, e ainda expressões, gestos, imagens, etc. O que dá a estes produtos [sons, expressões, gestos, imagens, etc.] a capacidade de servir de meio de transmissão de ideias a outro indivíduo, é, quer uma relação interior directa com as referidas ideias (vejamos por exemplo um grito de dor, um gesto de cólera), quer uma ligação produzida por uma associação de ideias, em que portanto a ideia directamente relacionada com o instrumento psíquico [sons, expressões, gestos, imagens, etc.] constitui o tempo de ligação entre estes e a ideia comunicada; este é o caso que se verifica na língua (PAUL, 1966 [1880], p. 22-23, grifo nosso em negrito, grifo do autor em itálico).

No trecho acima, Paul procura explicitar de que modo uma associação que ocorre de maneira particularizada em um único indivíduo é transmitida a outro dando origem à mudança das associações regulares da língua. Para tanto, ele trata da descrição dos fenômenos que ocorrem na "alma dos indivíduos", fazendo menção à associação estabelecida entre os produtos psíquicos, isto é, entre a própria ideia e os sons, expressões, gestos e imagens, definidora da relação interior direta em cada indivíduo, e a outro tipo de ligações produzido pela nova associação de ideias.

Em comparação com a teorização saussuriana, a reflexão apresentada por Paul, sobre os processos fundamentais criadores das formas linguísticas, nos parece pouco esclarecedora. Para nós, isso se deve ao fato de que, para além de observar a existência das associações entre as ideias e os sons, Saussure se preocupou em criar um ambiente teórico propício para que uma reflexão plausível sobre tais relações fosse possível. Desse modo, no estudo de Saussure, vemos que as definições em torno das associações entre ideias e sons são cotejas, em primeiro lugar, por uma preocupação terminológica, como aquela apresentada por ele na definição das partes do signo linguístico ${ }^{8}$ e, em segundo lugar, por

\footnotetext{
8 “A ambiguidade desapareceria se designássemos as três noções aqui presentes por nomes que se relacionem entre si, ao mesmo tempo [em] que se opõem. Propomo-nos a conservar o termo signo para designar o total, e
} 
princípios e outras noções que de modo conjunto explicam o fenômeno linguístico, tal qual a noção de valor.

A reflexão apresentada pelo neogramático no trecho anterior, assim como as distinções apresentadas por ele, neste trecho, como afirmamos, não parecem esclarecedoras. Todavia, como veremos a partir de trechos posteriores, trata-se das relações diretas e das indiretas. É, pois, a transformação das relações diretas - ou usuais - em relações indiretas - ou ocasionais ${ }^{9}$ - que Paul procura compreender. Continuemos a observar a explicação dada pelo autor:

Partimos do princípio de que a alma estranha tem, com o mundo que a cerca, as mesmas relações que a nossa, que as mesmas impressões físicas produzem nela ideias iguais às que produzem na nossa, e que estas ideias se ligam de modo idêntico. Um certo grau de concordância na organização espiritual e corporal, na natureza que os cerca e nas vivências, é portanto a condição prévia para uma possibilidade de entendimento entre indivíduos diferentes. Quanto maior for esta concordância, tanto mais fácil será o entendimento. Ao contrário, toda e qualquer divergência nestes campos tem como consequência que não só sejam possíveis, como necessariamente sobrevenham a incompreensão, o entendimento parcial ou o mal-entendido (PAUL, 1966 [1880], p. 23).

No que se refere às relações diretas e que dizem respeito à associação entre a ideia e os sons, ou imagens e gestos, devem ser idênticas nos diferentes indivíduos de uma mesma "entidade linguística" - terminologia utilizada pelo autor para se referir a uma dada língua para que haja entendimento entre eles. Nesta passagem, além da identidade entre as relações diretas, Paul parece atribuir à concordância da organização espiritual e corporal, à natureza que cerca os indivíduos e à vivência de cada um deles a condição prévia para o entendimento entre eles. Embora Paul se atente para o fato de que tais fenômenos não são de uma mesma natureza, ao afirmar que "[...] nem tudo o que torna possível a acção dum indivíduo sobre outro é psíquico" (PAUL, 1966 [1880], p. 22), a nosso ver, Paul parece dar uma mesma importância a eles. Para ele, quanto maior for a concordância entre estes elementos maior será a possibilidade de compreensão entre falantes. Partindo disso,

a substituir conceito e imagem acústica respectivamente por significado e significante; esses dois termos têm a vantagem de assinalar a oposição, que os separa, quer entre si, quer do total de que fazem parte. Quanto a signo, se nos contentamos com ele, é porque não sabemos por que substituí-lo, visto não nos sugerir a língua usual nenhum outro" (SAUSSURE, 2012, p. 107).

${ }^{9}$ Os termos usuais e ocasionais são utilizados por Paul no estudo da mudança semântica. Pare ele, as significações usuais são aquelas de concordância geral e as ocasionais são aquelas utilizadas pelo individuo em ocasiões específicas "a pessoa que fala relaciona com a palavra ao pronunciá-la, [...] ela espera que também o ouvinte relacione com a mesma palavra” (PAUL, 1966 [1880], p. 83). Como veremos, as relações diretas também são entendidas a partir da concordância geral, enquanto as relações indiretas são resultantes da criação de novas ligações ou associações feitas individualmente na "alma dos indivíduos". 
observamos que Paul atribui o funcionamento da língua - indistinto do funcionamento da fala, uma vez que essa delimitação só foi possível nos estudos saussurianos - em outras palavras, a efetividade das "relações diretas" na comunicação entre os indivíduos, a fenômenos não linguísticos: a organização espiritual e corporal, a natureza que cerca os indivíduos e vivência deles. Ora, era preciso antes, como observa Saussure, distinguir a linguística da fala e a linguística da língua ${ }^{10}$, bem como seus elementos internos dos elementos externos a ela para uma melhor compreensão do fenômeno linguístico ${ }^{11}$.

Ainda sobre as relações diretas e indiretas, Paul afirma que:

É através dos meios físicos, que estão diretamente relacionados com as ideias comunicadas, que o entendimento vai mais longe; pois este emana muitas vezes já da concordância geral existente e na natureza humana. Por outro lado, onde a relação é indirecta, parte-se do princípio de que a mesma associação se produziu nas diferentes almas, o que faz pressupor uma experiência idêntica (PAUL, 1966 [1880], p. 23).

Como se vê nesta passagem, para Paul o entendimento das associações entre os meios físicos e as ideias comunicadas é resultante, ele aponta - muitas vezes, de uma concordância geral e na natureza humana. Enquanto no que tange às relações indiretas, para que seu entendimento seja efetivo, pressupõe-se que elas tenham ocorrido anteriormente em almas diferentes a partir de experiências idênticas, ainda que, como vimos no primeiro excerto analisado, Paul também trate do modo de transmissão das relações indiretas nascidas em uma única "alma” para outra.

O objetivo de abordar essas relações pode ser identificado no excerto a seguir. Nele, Paul nos deixa entrever que a reflexão sobre tais relações e a natureza delas - embora esta última seja pouquíssimo explicitada - tem por objetivo abordar as transformações das relações diretas em relações indiretas que se cristalizarão em associações diretas:

Se perguntarmos agora por que razão afinal o indivíduo, apesar de ter de criar ele próprio o seu círculo de ideias, recebe, contudo, da sociedade uma determinada direção para a sua evolução espiritual e uma instrução muito mais elevada do que poderia alcançar numa vida isolada, teremos que designar como ponto essencial a transformação de associações indirectas em directas. Esta transformação produz-se dentro da alma isolada, mas o

10 "O estudo da linguagem comporta, portanto, duas partes: uma essencial, tem por objeto a língua, que é social em sua essência e independente do indivíduo - esse estudo é unicamente psíquico; outra, secundária, tem por objeto a parte individual da linguagem, vale dizer, a fala, inclusive a fonação - é psicofísica" (SAUSSURE, 2012, p. 51).

11 "Nossa definição da língua supõe que eliminemos dela tudo o que lhe seja estranho ao organismo, ao seu sistema: tudo quanto se designa pelo termo Linguística Externa” (SAUSSURE, 2012, p. 53). 
resultado é transmitido a outras almas, naturalmente por meios físicos, da forma que descrevemos (PAUL, 1966 [1880], p. 24, grifos do autor).

Nota-se que são as transformações de associações, segundo Paul, que ocorrem de maneira individualizada, e o modo como elas são transmitidas aos outros indivíduos da sociedade ou às outras "almas" que instigam o neogramático. Pelo trecho acima, observamos que algumas questões de ordem mais geral parecem ter sua importância reduzida e são precipitadamente tratadas, como na afirmação de que o indivíduo que cria ele próprio seu círculo de ideias, embora receba da sociedade direção para sua "evolução espiritual".

\section{Os agrupamentos linguísticos: entre a Gramática e a realidade linguística}

Para além dos fenômenos que ocorrem na associação dos produtos psíquicos, isto é, as ideias e os sons, e de suas respectivas transformações, a noção de relação é também mobilizada, mesmo que de forma panorâmica, na reflexão sobre os agrupamentos de palavras e suas transformações, no capítulo nomeado "Generalidades sobre a natureza da evolução da língua". Neste capítulo, Paul retoma a distinção entre gramática comparada e gramática histórica, evidenciando que por comparação chega-se, por exemplo, à conclusão de que há "certa regularidade nas relações mútuas, mas por este processo não chegamos a ser esclarecidos sobre o verdadeiro carácter das transformações realizadas" (PAUL, 1966 [1880], p. 34).

Segundo o neogramático, os grupos de todos os sons que um indivíduo tenha dito, ouvido e imaginado e as respectivas ideias a eles associadas, isto é, "os múltiplos complexos em que se formaram, na alma de cada um, os elementos da língua” (PAUL, 1966 [1880], p. 34), pertencem ao domínio da história e, para uma compreensão da evolução linguística, é preciso que tenhamos consciência dele. Saussure, por sua vez, em sua reflexão, defenderá que os signos, bem como as relações sintagmáticas e associativas, noções que podem ser minimamente relacionadas, respectivamente, aos "agrupamentos linguísticos" menores e maiores tratados por Paul, são realidades sincrônicas da língua e, portanto, não constituem fator histórico.

Ainda, sobre tais agrupamentos, Paul afirma: 
Os grupos de sons e os grupos de movimentos associam-se entre si. A ambos associam-se às ideias, às quais elas servem de símbolos. Não só as ideias de significados das palavras, mas também as de relações sintáticas. E não só as palavras isoladas, mas séries maiores de sons - frases completas - se associam diretamente ao conteúdo ideológico que se lhes emprestou. Estes grupos, que, pelo menos originariamente, nos vêm do meio ambiente, constituem-se agora, na alma de cada indivíduo, em associações muito mais ricas e complexas, que só em muito pequena parte se realizam conscientemente, continuando então a actuar no subconsciente. [...] Assim se associam entre si diferentes empregos que se aprenderam duma palavra ou duma expressão. Assim se associam os diferentes casos do mesmo substantivo, os diferentes tempos, modos, pessoas do mesmo verbo, os mesmos derivados duma só raiz, em virtude de semelhança de som e de significado; além disso, todas as palavras que têm a mesma função, por exemplo todos os substantivos, todos os adjetivos, todos os verbos; [...] (PAUL, 1966 [1880], p. 35).

Com base no trecho acima, nota-se que os agrupamentos dos elementos da língua, de que fala Paul, são entendidos por ele de um modo peculiar. Embora o neogramático evidenciasse uma organização dos elementos da língua, que se dá "na alma de cada indivíduo" a partir de "associações muito mais ricas e complexas", esta organização foi abordada pelas categorias gramaticais. Segundo o autor, essas associações, que podem se produzir-se sem consciência, de forma alguma devem ser confundidas "com as categorias que abstraímos pela reflexão gramatical, embora elas habitualmente se correspondam" (PAUL, 1966 [1880], p. 36). Paul demonstra, então, uma consciência da distinção entre as associações e as categorias abstraídas da reflexão gramatical, apesar disso, essa distinção parece produzir poucos efeitos, nessa teoria, se a compararmos com o que é proposto por Saussure.

Saussure, longe de acreditar que as associações linguísticas e as categorias "habitualmente" se correspondem, tece fortes críticas ao entendimento do fato linguístico pelos conceitos e subdivisões estabelecidos pela gramática. Ao tematizar sobre as realidades linguísticas ou de elementos concretos da língua, Saussure se questiona sobre se as classificações feitas pela gramática seriam realidades linguísticas. Para o linguista, tais classificações, como os substantivos e os adjetivos, são defeituosas ou incompletas e tratam-se de "conceitos forjados pelos gramáticos" sobre os quais não podemos afirmar ao certo se "correspondem realmente a fatores constitutivos do sistema da língua" (SAUSSURE, 2012, p. 155).

Tal crítica se acentua, ainda, no capítulo “A gramática e suas subdivisões”. Nele Saussure propõe uma substituição das definições e divisões tradicionais por "divisões 
racionais", nos dando vista a um distanciamento daquilo proposto pelos estudiosos do final do século XIX. Vejamos:

Nossa definição [de gramática] não concorda com aquela, mais restrita, que dela se dá geralmente. É, com efeito, à morfologia e à sintaxe reunidas que se convencionou chamar de Gramática, ao passo que a lexicologia ou a ciência das palavras foi dela excluída. Mas, em primeiro lugar, tais divisões correspondem à realidade? Estão em harmonia com os princípios que acabamos de formular? A morfologia trata das diversas categorias de palavras (verbos, substantivos, adjetivos, pronomes etc.) e das diferentes formas de flexão (conjugação, declinação). Para separar esse estudo da sintaxe, alega-se que esta tem por objetivo as funções próprias das unidades linguísticas, ao passo que a morfologia só se ocupa de sua forma [...]. Tal distinção é, porém, ilusória [...] (SAUSSURE, 2012, p. 183-184).

Para Saussure, as divisões tradicionais propostas pela Gramática, e amplamente utilizadas pelos neogramáticos, embora tenham sua utilizada prática, "não correspondem a distinções naturais e não estão unidas por nenhum vínculo lógico" (SAUSSURE, 2012, p. 185). Assim, pensando em uma "divisão racional", Saussure estabelece que a distinção entre morfologia, sintaxe e lexicologia pode ser, no fundo, entendida pela sincronia. Segundo ele:

\begin{abstract}
Somente a distinção entre as relações sintagmáticas e as relações associativas sugere um modo de classificação que se impõe por si mesmo, o único que se pode pôr como base do sistema gramatical. Tudo o que compõe um estado de língua pode ser reduzido a uma teoria dos sintagmas e a uma teoria das associações. [...] Seria necessário poder reduzir dessa maneira cada fato à sua ordem, sintagmática ou associativa, e coordenar toda a matéria da Gramática sobre esses dois eixos naturais; somente essa repartição mostraria o que cumpre mudar nos quadros usuais da Linguística sincrônica (SAUSSURE, 2012, p. 185-186).
\end{abstract}

A passagem acima apresenta de modo bastante claro o que temos argumentado que ao estabelecer um novo modo de conceber as relações em linguística, a saber, a partir do entendimento de língua enquanto um sistema de signos regido pelas relações sintagmáticas e associativas, e não mais pelas relações empregadas pela gramática e também pelos neogramáticos na divisão das palavras da língua em categorias, Saussure se distancia significativamente de seus contemporâneos, constituindo as bases para uma nova era dos estudos da língua. Para ele, a reflexão linguística operada sobre as categorias gramaticais mostra-se inviável, uma vez que elas não dizem respeito à realidade da língua, são resultado de abstrações; é preciso operar sob os eixos naturais ou reais das relações linguísticas, a saber: o eixo das relações sintagmáticas e o eixo das relações associativas. 


\section{A relação no estudo da mudança semântica, da mudança fonética e da analogia}

Ainda em análise à proposta de Paul, observamos que as reflexões em torno dos grupos linguísticos, além de ser forçada no que tange às classificações apresentadas por elas, são mobilizadas, ainda, unicamente em função da mudança linguística. É a modificação destes conjuntos, explicitados tão rapidamente e a partir de uma terminologia tão rudimentar, que interessa a Hermann Paul. São as mudanças das relações estabelecidas no complexo de agrupamentos que constituem seu alvo de interesse e não o funcionamento das relações propriamente ditas. Isso é o que podemos entrever na declaração apresentada no excerto transcrito a seguir, no qual Paul deixa claro que se absterá de examinar as leis gerais que regem o funcionamento dos agrupamentos - para ele, já claras no estudo de Steinthal em "Psicologia e Linguística" -, uma vez que seu objeto é apenas o de dar uma ideia do conteúdo e da ação dos agrupamentos linguísticos.

Todas as manifestações da atividade da fala brotam deste espaço obscuro do subconsciente, existente na alma. Nele encontram-se - como forma psíquica altamente complexa, que consta de grupos diversos de ideias intimamente ligados uns aos outros - todos os recursos linguísticos que cada um tem ao seu dispor, e, podemos mesmo dizer, um pouco mais do que aqueles de que pode dispor em circunstâncias normais. Não nos compete aqui examinar as leis gerais segundo as quais se formam estes grupos. Para isso remeto para a introdução de Steinthal à Psicologia e Linguística. Aqui só nos interessa dar uma ideia do conteúdo e acção desses grupos (PAUL, 1966 [1880], p. 35).

No que se refere à mudança fonética, tratada por Paul no terceiro capítulo de seu livro, o autor apresenta os diferentes tipos de mudança que ocorrem no âmbito dos fonemas. Nesse capítulo, a noção de relação aparece de modo bastante tímido apenas para a explicação das modificações que ocorrem entre os sons, a saber: a metátese, assimilação e dissimilação.

Sobre a metátese, Paul (1966 [1880], p. 71) afirma que é preciso distinguir duas espécies principais. A primeira é "A inversão de dois sons que se seguem imediatamente, como o anglo-saxão fix junto de fisc, ácsian junto de áscian [...]”. A segunda, por sua vez, acontece quando "dois sons geralmente afins, que não se seguem imediatamente, trocam as suas posições; a troca mais vulgar é a de $r$ e $l$, vide o velho-alto-alemão erila junto de elira [...]”, ou no português estupro junto de *estrupo. Em ambas as espécies, explicitadas por Paul a partir de inúmeros exemplos, observamos, então, que há uma alteração na posição ocupada pelos fonemas, criando uma nova relação ou correspondência no encadeamento deles. 
No que tange à assimilação, fenômeno a partir do qual um segmento da cadeia fonética adquire novos traços a partir da influência de outros sons também componentes da cadeia, Paul afirma que ela pode se dar entre dois sons não vizinhos e exemplifica com fenômenos entre línguas diferentes, como o "latim quinque de *pinque, germânico primitivo *finfi (fünf-cinco) [...]" (PAUL, 1966 [1880], p. 71). Como se vê, o segmento pi- do primeiro caso transformou-se em qui assimilando os traços de -que, o que resultou em quinque. No segundo caso, o segmento fün- assimilou os traços de $-f$ e resultou em finfi.

A dissimilação, por sua vez, ocorre mais frequentemente "entre dois sons não imediatos, em que um deles é substituído por um som só semelhante" (PAUL, 1966 [1880], p. 72). Este fenômeno, segundo Paul, também é frequente na substituição de $r$ por l. É o que ocorre, por exemplo, dentre os diversos casos apontando pelo autor, com os termos do latim médio almaria e pelegrinus, que resultaram em armarium e peregrinus.

No estudo da Mutação semântica, Paul retoma a reflexão introdutória proposta por ele sobre as transformações das relações entre as ideias e os sons. Segundo o linguista histórico, "a mutação semântica comporta-se numa coisa exatamente como a alteração fonética - produz-se por um desvio no emprego que cada um faz do usual, desvio esse que por sua vez se torna gradualmente usual” (PAUL, 1966 [1880], p. 83). Desse modo entendido, a mudança semântica ocorre, então, quando uma significação ocasional, isto é, empregada individualmente por um falante da língua em uma situação particular, passa a dar lugar a uma significação usual, que diz respeito às significações de concordância geral ou as significações regulares da língua. As significações ocasionais, para Paul, se diferem das usuais de um modo particular:

A significação ocasional é normalmente mais rica de conteúdo do que a usual, mas tem uma extensão mais limitada. Em primeiro lugar, salientaremos que a palavra ocasionalmente pode designar algo de concreto, enquanto que usualmente só designa coisa abstractas, uma noção geral, sob a qual podemos alojar diversas coisas concretas. Aqui e nas páginas seguintes entendo por concreto sempre alguma coisa que estabelecemos como existindo realmente, que está ligada a determinados limites de tempo e de espaço; por abstracto entendo uma noção geral, puro conteúdo ideológico em si, livre de limitações de tempo e espaço (PAUL, 1966 [1880], p. 83-84).

No capítulo dedicado à analogia, a noção de relação aparece, sobretudo, associada à noção de agrupamentos linguísticos, definida por Paul e apresentada por nós anteriormente. Nele, Paul retoma a definição de agrupamentos apontando a organização mútua dos elementos da língua observada por ele: 
[...] as palavras isoladas juntam-se às outras no espírito e daí resulta uma quantidade de grupos maiores ou menores. A atracção mútua baseia-se sempre numa concordância parcial do som ou da significação, ou da significação e som simultaneamente. Cada grupo não existe isoladamente ao lado dos outros: há grupos maiores que incluem vários mais pequenos, e dá-se um cruzamento recíproco dos grupos (PAUL, 1966 [1880], p. 117).

Tais grupos - como apontamos, vistos por Paul a partir de um viés gramatical, mas que evidenciam a existência de relações e associações no fenômeno linguístico - associam as formas, ou "as palavras isoladas", a partir da concordância total ou parcial dos sons ou das significações. Assim, há agrupamentos que se formam a partir da concordância fonética, da concordância de significação, da concordância etimológica e mesmo da concordância de associações sintáticas. Segundo Paul, "não há assim dizer palavra nenhuma, seja em que língua for, que esteja absolutamente fora de qualquer um dos referidos grupos. Encontram-se sempre outras de qualquer modo semelhantes, a que ela se pode encostar" (PAUL, 1966 [1880], p. 120).

A noção de agrupamentos linguísticos movimentada por Paul, para a qual a noção de relação é imprescindível, mostra-se de extrema importância para a reflexão que o linguista histórico tece neste capítulo, isso porque, como veremos no excerto a seguir, ela é fundamental para a atividade combinatória operada pelo indivíduo na criação de palavras, a qual Paul denomina "formação por analogia", importante fator de evolução da língua. Vejamos:

As palavras e grupos de palavras que empregamos na conversação só em
parte se criam por mera reprodução de memória do que aprendemos
antes. Tem mais ou menos a mesma influência sobre a fala uma atividade
combinatória que se baseia na existência dos grupos de proporções. A
combinação consiste de certo modo na redução duma equação de proporções
através da criação dum segundo membro de proporção segundo o
modelo de proporções análogas já tornadas correntes, para uma palavra
igualmente corrente. A este processo chama-se formação por analogia. É
um facto inegável que uma quantidade de formas e de associações
sintácticas jamais introduzidas de fora no espírito, não só podem ser
criadas com a ajuda dos grupos de proporções, como de facto são
contínua e firmemente criadas, sem que a pessoa que fala tenha a
sensação de abandonar o chão firme do aprendido (PAUL, 1966 [1880],
p. 120-121).

Nota-se, de acordo com o que é dito por Paul, que o processo de criação das palavras por meio da analogia constitui na reprodução daquilo já aprendido pelo indivíduo por meio de uma atividade combinatória. Desse modo, entende-se que por meio do fenômeno analógico as palavras são criadas à luz da relação estabelecida com outras 
palavras já correntes numa dada língua, tal como esse fenômeno também entendido no interior da teoria saussuriana. Entretanto, nesta última, a analogia é definida unicamente como um processo de criação que pode ocasionar mudança, por isso, é concebida como um fato sincrônico. É pelo fato de as palavras serem criadas sob a luz de outras que Paul ressalta que não há estranheza, ou em suas palavras, "a sensação de abandonar o chão firme do aprendido" (PAUL, 1966 [1880], p. 121) por parte da pessoa que fala, tendo em vista que já há na língua formas que se assemelham àquelas ocasionalmente criadas por ele.

De um modo geral, nossa leitura da proposta teórica de Hermann Paul, apresentada na "Introdução" e nos capítulos "Generalidades sobre a natureza da evolução da língua", "A mutação Fonética", "A mutação semântica" e "Analogia" nos mostrou que a noção de relação é movimentada em diferentes momentos da reflexão do neogramático, a saber: i) na definição do objeto, isto é, as relações no tempo à luz da noção de evolução e, concomitantemente, em sua distinção dos estudos da gramática comparada, que estuda as relações de famílias aparentadas; ii) no entendimento das associações diretas que acontecem entre o conteúdo psíquico e o conteúdo físico e que se transformam associações indiretas, transformação que, de modo geral, explica o fenômeno da mudança; iii) no entendimento da associação que acontece no interior dos agrupamentos linguísticos e entre tais agrupamentos; mais timidamente iv) no estudo da mutação fonética e v) mutação semântica; e também vi) na reflexão sobre a analogia.

\section{Considerações finais}

Embora, como vimos, a noção de relação apareça em diferentes momentos da reflexão proposta pelo neogramático Hermann Paul, a nosso ver, o movimento realizado em torno dessa noção, neste estudo, parece se distinguir daquele realizado por Saussure. Isso porque, como podemos ler na edição do Curso de Linguística Geral, Saussure restabelece as relações a serem estudadas, definindo-as, delimitando-as e demarcando o lugar delas no interior do estudo linguístico, o que dá a elas lugar de destaque na reflexão do mestre genebrino.

Ao passo que esta noção parece ocupar lugar secundário no estudo desenvolvido por Paul, uma vez que ela é mobilizada, especialmente, na compreensão da evolução linguística. Para além de compreender as relações constitutivas do fenômeno linguístico em 
si, Paul procura desvendar os mistérios da mudança, mobilizando, apenas ocasionalmente, uma reflexão mais geral sobre os fenômenos que permanecem a despeito da evolução.

Isso nos permite vislumbrar uma mudança de estatuto da noção de relação de um viés para outro. Nos estudos propostos por Saussure, a noção de relação possui importantes implicações teóricas, dado que ela é movimentada na distinção entre os fenômenos diacrônicos e sincrônicos, na definição de unidade linguística e, sobretudo, na definição do objeto linguístico e na explicação de seu funcionamento, o que culminará em uma mudança radical no campo de estudos da língua. Enquanto que, no estudo de Paul, a noção de relação, embora constitua pressuposto para o entendimento do objeto de investigação histórica, isto é, a mudança, é mobilizada apenas secundariamente.

Como vimos, Paul, assim como seus contemporâneos e antecessores, tinha consciência da existência de relações no fenômeno linguístico. Ainda que por meio de uma terminologia rudimentar, Paul valeu-se das relações para diferenciar o método utilizado pela Linguística Histórica daquele utilizado pela Gramática Comparada, para tratar das relações entre os processos psíquicos que constituem a língua e ainda para estabelecer que os elementos linguísticos não se dão de forma isolada, mas a partir de agrupamentos. Para nós, embora a noção de relação estivesse presente nesta reflexão, foram poucas as consequências teóricas que dela resultaram na investigação histórico-comparatista.

Embora os neogramáticos apresentem uma preocupação com aquilo que é geral, como pode ser observado nas reflexões de Hermann Paul, as relações fundamentais, aquelas reguladoras do funcionamento linguístico, constitutivas dos signos, seja em seu interior, seja entre eles, são tomadas como dadas e aparecem, principalmente, em função das explicações evolutivas. Isso nos faz concordar com Saussure quando, na Introdução do CLG, aponta que, embora esta escola tenha prestado grandes serviços ao estudo da Linguística, como o de demonstrar a inviabilidade do entendimento da língua como um organismo e o de afirmá-la como produto do coletivo, ela deixou de se preocupar com problemas fundamentais da Linguística Geral.

Para Saussure, como testemunha a carta a Meillet, era imprescindível que o estudo histórico da língua fosse antecedido por uma reflexão que explicasse aos estudiosos qual espécie de objeto é a língua em geral. Era preciso dar um passo atrás e pensar a natureza do objeto linguístico. Era preciso, antes, distinguir os fenômenos históricos dos fenômenos sincrônicos, em outras palavras, era preciso distinguir a língua propriamente dita de sua 
história. Era preciso tirar consequência da existência de relações no fenômeno linguístico.

Ao tematizar sobre as diferentes ordens de relações Linguísticas, Saussure afirma:

Após ter concedido um lugar bastante grande à História, a Linguística voltará ao ponto de vista estático da Gramática tradicional, mas com um espírito novo e com outros processos, e o método histórico terá contribuído para esse rejuvenescimento; por via indireta, será o método histórico que fará compreender melhor os estados de língua. A Gramática antiga via somente o fato sincrônico; a Linguística nos revelou uma nova ordem de fenômenos; isso, porém não basta: é necessário fazer sentir a oposição das duas ordens e dai tirar todas as consequências que comporta. (SAUSSURE, 2012, p. 124, grifo nosso).

Como pode ser lido na edição do Curso de Linguistica Geral, o linguista genebrino parece ter amplamente se preocupado em "tirar todas as consequências" que a distinção entre as relações sincrônicas e as relações diacrônicas pode comportar. Para além de observar que há uma diferença entre tais ordens de relações, como já observava Paul, Saussure delineará ainda outros fatores consequentes dessa distinção, os quais podem ser lidos, por exemplo, na teoria do valor linguístico proposta por ele.

\section{Referências}

BENVENISTE, E. Lettres de Ferdinand de Saussure à Antoine Meillet. Cahiers Ferdinand de Saussure, Revue suisse de linguistique générale, no 12, p. 89-130. Genève: Librairie Droz, 1964.

DE MAURO, T. Notes. In: SAUSSURE, F. Cours de Linguistique Générale. Édition critique preparé par Tullio De Mauro. Paris: Payot, 1973.

MARQUES, A. C. M. Da relação à estrutura: a influência do pensamento saussuriano em meados do século XX. Domínios de Linguagem, v. 9, nº 5, jan./jun. 2015.

A (re)escrita dos fenômenos linguísticos sob à luz da relação: o ponto de vista saussuriano. Eutomia, v. 17, no 1, jul. 2016.

A fecundidade teórica da noção de relação na delimitação entre sincronia e diacronia: uma análise de manuscritos saussurianos. Fórum Linguístico, v. 14, nº 2, jun. 2017.

A natureza relacional dos conceitos fundadores da Linguística Moderna: uma leitura do Curso de Linguística Geral. Domínios de Linguagem, v. 12, nº 1, jan./jun. 2018.

NORMAND, C. Saussure: uma epistemologia da Linguística. In: SILVEIRA, Eliane M. (Org.). As bordas da linguagem. Uberlândia: EDUFU, 2011. 
PAUL, H. Princípios fundamentais da história da língua. Trad. Maria Luisa Schemann. Lisboa: Fundação Calouste Gulbenkian, 1966 [1880].

SAUSSURE, F. Curso de linguística geral. 34 ed. Organizado por Charles Bally, Albert Sechehaye com a colaboração de Albert Riedlinger. Trad. A. Chelini, J. P. Paes e I. Bliksten. São Paulo: Cultrix, 2012.

\begin{abstract}
In this paper, we present an analysis of the notion of relation at theoretical reflection of the neogrammarian Hermann Paul in comparison with the theoretical elaboration of Ferdinand de Saussure. This analysis will show how the notion of relation is treated, in Paul's reflection, in a secondary way, mainly for the understanding of change, unlike what bappens in Saussurian reflection, in which it occupies a prominent place. Therefore, we will proceed with a bibliographical revision of Fundamental Principles of the History of the Language by Hermann Paul emphasizing passages in which the notion of relation is mobilized by him and, timely, we will establish a comparison with the theoretical Saussurian proposal that appears in the edition of the Course in General Linguistics.
\end{abstract}

Keywords: Relation. Linguistics. Neogrammarian. Ferdinand de Saussure

Recebido em: 07/05/2018.

Aceito em: 06/07/2018. 